\title{
BMJ Heat stress, health and well-being: Open findings from a large national cohort of Thai adults
}

\author{
Benjawan Tawatsupa, ${ }^{1,2}$ Vasoontara Yiengprugsawan, ${ }^{1}$ Tord Kjellstrom, ${ }^{1,3}$ \\ Sam-ang Seubsman, ${ }^{4}$ Adrian Sleigh, ${ }^{1}$ the Thai Cohort Study Team
}

To cite: Tawatsupa B, Yiengprugsawan $\mathrm{V}$, Kjellstrom $\mathrm{T}$, et al. Heat stress, health and well-being: findings from a large national cohort of Thai adults. BMJ Open 2012;2:e01396. doi:10.1136/bmjopen-2012001396

- Prepublication history and additional material for this paper are available online. To view these files please visit the journal online (http://dx.doi.org/10.1136/ bmjopen-2012-001396).

Received 30 April 2012 Accepted 5 October 2012

This final article is available for use under the terms of the Creative Commons Attribution Non-Commercial 2.0 Licence; see http://bmjopen.bmj.com

For numbered affiliations see end of article

\section{Correspondence to} Benjawan Tawatsupa; ben_5708@hotmail.com

\section{ABSTRACT \\ Objectives: This study aims to examine the association between self-reported heat stress interference with daily activities (sleeping, work, travel, housework and exercise) and three graded-holistic health and well-being outcomes (energy, emotions and life satisfaction).}

Design: A cross-sectional study.

Setting: The setting is tropical and developing countries as Thailand, where high temperature and high humidity are common, particularly during the hottest seasons.

Participants: This study is based on an ongoing national Thai Cohort Study of distance-learning openuniversity adult students ( $N=60569)$ established in 2005 to study the health-risk transition.

\section{Primary and secondary outcome measures:}

Health impacts from heat stress in our study are categorised as physical health impacts (energy levels), mental health impacts (emotions) and well-being (life satisfaction). For each health and well-being outcome we report ORs and $95 \%$ Cls using multinomial logistic regression adjusting for a wide array of potential confounders.

Results: Negative health and well-being outcomes (low-energy level, emotional problems and low life satisfaction) associated with increasing frequency of heat stress interfering with daily activities. Adjusted ORs for emotional problems were between 1.5 and 4.8 and in general worse than energy level (between 1.31 and 2.91) and life satisfaction (between 1.10 and 2.49). The worst health outcomes were when heat interfered with sleeping, followed by interference with daily travel, work, housework and exercise.

Conclusions: In tropical Thailand there already are substantial heat stress impacts on health and well-being. Increasing temperatures from climate change plus the ageing and urbanisation of the population could significantly worsen the situation. There is a need to improve public health surveillance and public awareness regarding the risks of heat stress in daily life.

\section{INTRODUCTION}

Over the last decade interest has grown in the impact of global warming on human health. ${ }^{1}$

\section{ARTICLE SUMMARY}

Article focus

- To examine the association between self-reported heat stress interference with daily activities (sleeping, work, travel, housework and exercise) during hot season and three graded holistic health outcomes (energy, emotions and life satisfaction) in Thailand.

Key messages

- Negative health and well-being outcomes (low energy level, emotional problems and low life satisfaction) associated with increasing frequency of heat stress interfering with daily activities.

- The worst health outcomes were when heat interfered with sleeping, followed by interference with daily travel, work, housework and exercise.

- The results from this study point to the need for improving public health surveillance and public awareness regarding the risks of heat stress in daily life in a tropical country like Thailand.

Strengths and limitations of this study

- The possible limitation of self-reports, but note that questions on heat stress and health outcomes were in different parts of the questionnaire.

- The strength of this study is its large scale with participation from a national group of adults embedded in the socioeconomic mainstream of Thai society and used the comprehensive questionnaire which captures a detailed assessment of health and an array of geodemographic, environmental and social attributes.

Increasing heat stress has substantial adverse effects on population mortality and morbidity. ${ }^{2-5}$ This information is from developed and temperate countries ${ }^{3}$ and leaves unanswered questions for tropical and developing countries where high temperature and humidity are common. Furthermore, heat stress in tropical cities is increasing due to urban heat island effects caused by industrial development and urbanisation in developing countries. ${ }^{6}$

Heat stress can have a major influence on daily human activities. The body absorbs 
external heat due to high air temperature and humidity, low air movement and high solar radiation; as well, some physical activities generate heat internally. ${ }^{7}$ Excess heat exposure during normal daily activities creates a high risk of recurrent dehydration and can cause other effects on physical health (eg, exhaustion, heat cramps, heat stroke or death). ${ }^{7}$ Heat stress affects mood, increases psychological distress and mental health problems, ${ }^{8-10}$ and also reduces key human psychological performance variables. ${ }^{11}$

Other heat stress impacts may arise from increased mistakes in daily activities and accidental injuries. As well, disturbed sleep and degraded physical performance from heat exhaustion reduce work capacity and lead to loss of income. ${ }^{812} 13$ Populations at risk of heat stress are not only the elderly but also young people and adults who are more likely to carry out heavy labour outdoors or work indoors without air conditioning or other effective cooling systems during the hot season. ${ }^{8} 1214$

In tropical Thailand, hot and humid conditions are common, especially in the hot season (March-June). The monthly maximum, mean and minimum temperatures averaged from 1999 to 2008 were around $33^{\circ} \mathrm{C}$, $27^{\circ} \mathrm{C}$ and $22^{\circ} \mathrm{C}$, respectively, with the averaged relative humidity at $75 \%$. The monthly maximum temperatures averaged during 10 years varied little by region $\left(32-33^{\circ} \mathrm{C}\right)$ and were highest in the North region during April $\left(40^{\circ} \mathrm{C}\right)$ and lowest in the same region during December $\left(24^{\circ} \mathrm{C}\right) .^{15}$

Global warming (or 'global heating' may be a better description in relation to Thailand) is now causing increasing alarm in many tropical areas. For example, from 1951 to 2003 , the monthly mean maximum temperature in Thailand increased by $0.56^{\circ} \mathrm{C}$ and the monthly mean minimum temperature increased even more at $1.44^{\circ} \mathrm{C}^{16}$ Heat stress is already a concern in Thailand and the observed trends indicate further increase in air temperature. ${ }^{17} \mathrm{~A}$ recent study of occupational heat stress in Thailand by Langkulsen et $a l^{18}$ revealed a very serious problem ('extreme caution' or 'danger') in an array of work settings (they tested a pottery factory, a power plant, a knife manufacture site, a construction site and an agricultural site).

Heat stress in Thailand, its effects and pathways to exposure have been reported for two cities ${ }^{1920}$ and for workers. ${ }^{10}{ }^{21}$ However, there is no available information on how much heat interferes with normal daily activities and heat stress effects on health and well-being in the general Thai population. Here we report an investigation of association between heat stress interference with daily activities and health and well-being in a large national cohort of young and middle-aged Thai adults.

\section{METHODS}

\section{Study population}

In 2005, a baseline questionnaire was mailed out to adult students enrolled at Sukhothai Thammathirat Open University. The questionnaire was developed by a multidisciplinary team in both Thailand and Australia to cover a wide range of topics for a longitudinal study of the Thai Health-Risk Transition-transformation of the health-risk and outcome pattern in Thailand as infectious diseases recede and chronic diseases emerge. Overall, 87134 distance-learning students aged 15-87 years responded from all areas of Thailand. Cohort participants were generally similar to the population of Thailand, especially in the 30-39 years age group, for sex ratio, income and geographical location. ${ }^{22}$

Data collected included demographic, socioeconomic and geographic characteristics, physical and mental health status, personal well-being, health-service use, risk behaviours, injuries, diet, physical activity and family background. A 4-year follow-up was conducted in 2009 and the next one is due in 2013.

This report is based on the 2009 follow-up which included questions on heat interference with normal daily activities. The heat stress and health outcome measures (both described below) were in different parts of the questionnaire. They could not easily be linked in the respondent's mind so answers on these issues were independent. Covariates analysed are described with the results and include age, sex, marital status, geographic location, work status, smoking, drinking and body mass index.

\section{Measures of heat stress}

Questions related to heat stress were as follows: 'How often did the hot period this year interfere with the following activities?' (1) sleeping; (2) housework; (3) daily travel; (4) work and (5) exercise. Responses were 'not applicable-use air conditioning', 'never', '1-3 times per month', '1-6 times per week' and 'every day'. In this study, heat interference means heat stress causing an uncomfortable feeling when doing those daily activities. For analysis, we grouped self-reported heat stress into 'never', 'sometimes' (1-3 times per month), and 'often' (1-6 times per week or every day).

\section{Measures of health and well-being outcomes}

Health is defined by WHO as 'a complete state of physical, mental and social well-being and not merely the absence of disease or infirmity'. ${ }^{23}$ Health impacts from heat stress in our study are categorised as physical health impacts (eg, energy levels), mental health impacts (eg, emotions) and well-being (eg, life satisfaction). These three outcomes were selected because they match the holistic WHO health definition and represent fundamental health states. Many other more specific diseases would be expected to follow adverse outcomes for these health measures (see Discussion section).

To measure the physical and mental health impacts we used two questions from the standard Medical Outcomes Short Form Instrument (SF8) as follows: Energy: 'During the past four weeks, how much energy did you have?' Responses were 'very much', 'quite a lot', 'some', 'a little' and 'none'. For analysis we combined 
the last two categories. Emotions: 'During the past four weeks, how much have you been bothered by emotional problems (such as feeling anxious, depressed, or irritable)?' Responses were 'not at all', 'slightly', 'moderately', 'quite a lot' and 'extremely'. For analysis the last two categories were combined. To measure Well-being we used a standardised question: ${ }^{24} 25$ 'Thinking about your own life and personal circumstances, how satisfied are you with your life as a whole?' Scores range from 0 ('completely dissatisfied') to 10 ('completely satisfied').

\section{Data processing and statistical analysis}

Data scanning and editing involved checking the actual questionnaire response against its digital value using Thai Scandevet, SQL and SPSS software. For analysis we used multinomial logistic regression reporting ORs (adjusted for potential confounders) based on Stata V.12. ${ }^{26}$ For all three fundamental health outcomes (energy, emotions and well-being), the multinomial regression estimates the odds with which each of three increasingly severe abnormalities occurs relative to the odds of an optimal outcome. Individuals with missing data were excluded and so the totals presented vary a little according to the information available.

\section{Ethical considerations}

Ethics approval was obtained from Sukhothai Thammathirat Open University Research and Development Institute (protocol 0522/10) and the Australian National University Human Research Ethics Committee (protocol 2009/570). Informed written consent was obtained from all participants.

\section{RESULTS}

We first compared the 2005-2009 cohort to those who dropped out in 2009 (data not shown). The two groups were similar for age, sex ratio, employment, income and health outcomes studied here (energy levels, emotional problems and life satisfaction). Sociodemographic and health characteristics of the 60569 cohort members followed up in 2009 are presented in table 1 . There were slightly more women (54.8\%), $70 \%$ were aged less than 40 years and $55.3 \%$ were married. Nearly $20 \%$ reported household monthly income of less than 10000 Baht (300 \$US) per month, 73.2\% reported doing paid work and $56 \%$ resided in urban areas. Health-risk behaviours-regular smoking or regular alcohol drinking-were reported by $7.7 \%$ and $13.7 \%$, respectively. By Asian standards, ${ }^{27}$ half the cohort members were in the normal weight range, $9.5 \%$ were underweight, $18.8 \%$ were overweight and $22.1 \%$ were obese.

We noted that prevalence of 'often' heat interference for each daily activity are not much different in different regions of Thailand (33-42\% for daily travel, 29-38\% for work, $26-32 \%$ for housework, $23-29 \%$ for sleeping and $22-28 \%$ for exercise). Daily activities and heat interference frequency categories are summarised in table 2.
Table 1 Sociodemographic and health characteristics of Thai cohort members in 2009

\begin{tabular}{|c|c|c|}
\hline $\begin{array}{l}\text { Cohort } \\
\text { characteristics }\end{array}$ & $\mathrm{N}=60569$ & $\begin{array}{l}\text { Per } \\
\text { cent }\end{array}$ \\
\hline \multicolumn{3}{|c|}{ Demographic characteristics } \\
\hline \multirow[t]{2}{*}{ Sex } & Male & 45.3 \\
\hline & Female & 54.8 \\
\hline \multirow[t]{3}{*}{ Age (year) } & $\leq 29$ & 27.4 \\
\hline & 30-39 & 42.6 \\
\hline & $40+$ & 30.0 \\
\hline \multirow[t]{3}{*}{ Marital status } & Married & 55.3 \\
\hline & Never married & 37.9 \\
\hline & $\begin{array}{l}\text { Separated, divorced and } \\
\text { widowed }\end{array}$ & 6.8 \\
\hline \multicolumn{3}{|c|}{ Sociogeographic characteristics } \\
\hline \multirow{4}{*}{$\begin{array}{l}\text { Monthly income } \\
\text { (Baht) }^{\star}\end{array}$} & $\leq 10000$ & 18.8 \\
\hline & $10001-20000$ & 22.4 \\
\hline & $20001-30000$ & 35.7 \\
\hline & $>30000$ & 23.1 \\
\hline \multirow[t]{4}{*}{ Work status } & Doing paid work & 73.2 \\
\hline & Unpaid family workers & 7.3 \\
\hline & Seeking work & 2.2 \\
\hline & Others & 17.3 \\
\hline \multirow[t]{2}{*}{ Residence } & Rural residence & 44.0 \\
\hline & Urban residence & 56.0 \\
\hline \multicolumn{3}{|c|}{ Health-risk behaviours } \\
\hline & Regular smokers & 7.7 \\
\hline & Regular alcohol drinkers & 13.7 \\
\hline \multicolumn{3}{|l|}{$\begin{array}{l}\text { Body mass index } \\
\left(\mathrm{kg} / \mathrm{m}^{2}\right)\end{array}$} \\
\hline & Underweight $(<18.5)$ & 9.5 \\
\hline & Normal (18.5-22.9) & 49.5 \\
\hline & $\begin{array}{l}\text { Overweight at risk } \\
(23-24.9)\end{array}$ & 18.8 \\
\hline & Obese $(25+)$ & 22.1 \\
\hline
\end{tabular}

Heat interference 'often' was reported (in order of frequency) by $37.5 \%$ for daily travel, $34.5 \%$ for work, $29.9 \%$ for housework, $27.4 \%$ for sleeping and $25.9 \%$ for exercise. Health and well-being frequency outcomes are reported in table 3: $37.6 \%$ reported being very satisfied

Table 2 Daily activities and heat interference category among Thai cohort members in 2009

\begin{tabular}{|c|c|c|c|c|}
\hline \multirow{2}{*}{$\begin{array}{l}\text { Daily } \\
\text { activities } \\
\mathrm{N}=60569\end{array}$} & \multicolumn{4}{|c|}{ Heat interference (\%) } \\
\hline & $\begin{array}{l}\text { Not } \\
\text { applicable* }^{*}\end{array}$ & Never & Sometimes & Often \\
\hline Sleeping & 15.7 & 24.3 & 32.5 & 27.4 \\
\hline Housework & 1.3 & 37.1 & 31.7 & 29.9 \\
\hline Daily travel & 3.0 & 33.7 & 25.8 & 37.5 \\
\hline Work & 14.0 & 30.3 & 21.2 & 34.5 \\
\hline Exercise & 0.8 & 43.1 & 30.1 & 25.9 \\
\hline
\end{tabular}




\begin{tabular}{lc}
$\begin{array}{l}\text { Table } 3 \text { Health and well-being outcomes among Thai } \\
\text { cohort members in } 2009\end{array}$ \\
\hline Outcomes N=60569 & \\
\hline Overall life satisfaction (score ranged from \\
0 to 10) \\
9-10 very satisfied (highest) \\
8 (high) & 37.6 \\
6-7 (medium) & 28.8 \\
0-5 not very satisfied (low) & 21.7 \\
Energy level in the past 4 weeks & 12.0 \\
Very much & 14.9 \\
Quite a lot & 44.0 \\
Some & 32.0 \\
A little or none & 9.1 \\
Emotional problems in the past 4 weeks & \\
Not at all & 11.3 \\
Slightly & 48.4 \\
Moderately & 25.8 \\
Quite a lot/extremely & 14.5 \\
\hline
\end{tabular}

with their life, around $15 \%$ reported having very much energy in the past 4 weeks and close to $11 \%$ reported no emotional problems in the past 4 weeks.

Daily activities show a clear trend connecting increasing heat interference with worse health and well-being (table 4). For example, cohort members who experienced heat interference 'often' while sleeping reported 'extreme' emotional problems $(38.9 \%)$ much more frequently than 'no' emotional problems (16.4\%). A similar pattern for 'little or none' energy levels was found for those reporting heat interference 'often' while sleeping ( $36.1 \%$ vs $22 \%)$ and the same trend was observed for life satisfaction $(39.8 \%$ vs $22.2 \%)$. Daily travel and work have also shown strong gradients connecting frequent heat interference and worse health outcomes.

The multinomial logistic regression, adjusting for a wide array of potential confounders (see footnote in table 5), supported the descriptive results. For all three health outcomes, when each of the three graded-adverse outcome categories is compared with the optimal outcome, the relative odds ranged from 1.10 to 4.81 . Furthermore, most ORs show a dose-response (for each health outcome, more heat interference associates more strongly with a given grade of abnormality). And 95\% CIs for all ORs indicated statistical significance. So heat stress interfering with normal daily activities (sleep, housework, travel, work and exercise) associates with adverse outcomes for all three holistic measures of health. For example, reporting heat interference 'often' while sleeping was strongly associated with 'little or none' energy ( $\mathrm{OR}=2.23,95 \%$ CI 2.02 to 2.46 ), 'extreme' emotional problems $(\mathrm{OR}=4.81,95 \%$ CI 4.32 to 5.36$)$ and 'low' life satisfaction $(\mathrm{OR}=2.49,95 \%$ CI 2.28 to 2.71). At work, reporting heat interference 'often' was associated with 'little or none' energy ( $\mathrm{OR}=2.45,95 \%$ CI
2.22 to 2.71) and 'extreme' emotional problems $(\mathrm{OR}=3.64,95 \%$ CI 3.31 to 4.00$)$. Similar results were found during daily travel and doing housework. A statistically significant association was also found for heat inference during exercise but the magnitude of the effect was lower than for other activities.

\section{DISCUSSION}

Our study shows that climate-related heat stress in tropical Thailand associated with self-reported health and well-being if the heat interfered with daily activities such as sleep, housework, travel, work and exercise. The large study group included young and middle-age Thai adults, mostly doing paid work, with a little over half residing in urban areas. These cohort members are active and over $20 \%$ report often experiencing heat interference for daily activities during the hot season. Daily travel and work were sources of heat stress more often than other activities, probably because they involve time spent in traffic or outdoors during hot periods. Other activities such as housework have less heat stress than daily travel and work, perhaps because these activities are home based where air-conditioning or other ventilation is available.

We found those who report higher levels of heat stress interference with daily activities tend to also be the ones who have adverse health and well-being outcomes (low life satisfaction, low energy level and worse emotional problems). ORs of heat stress effects across all daily activities for emotional problems are between 1.55 and 4.81 and in general are worse than energy level effects (between 1.31 and 2.91) and life satisfaction effects (between 1.10 and 2.49). The worst health outcomes were for heat stress while sleeping followed by heat stress for daily travel, work, housework and exercise.

Our data are based on self-report by educated Thais and we note that questions on heat stress and health outcomes were in different parts of the questionnaire. Findings show strong and highly consistent trends especially for adverse health effects of frequent heat interference during sleep, daily travel and work. Elsewhere we have completed detailed analyses of associations between heat stress and self-reported health outcomes in the cohort using the questions from SF8. ${ }^{10}$ Our studied outcomes in this report were holistic fundamental measures of health. We can expect that those who had abnormal findings would also (already or eventually) manifest other more specific chronic diseases such as depression, obesity, hypertension and kidney disease. If so, the eventual burden of heat-related disease will be higher than currently recognised. ${ }^{28-30}$

Our findings add to some previous reports on working in hot environments which found that heat stress significantly reduced people's motivation to do their work. Lan et $a l^{31}$ assessed office workers' perceptions of thermal environment, emotions, well-being and motivation to work, and found that participants had 
Table 4 Frequency of heat interference with daily activities by health and well-being outcomes among cohort members Health and well-being outcomes $\mathrm{N}=60569$ Percentage of life satisfaction score ranged Percentage of energy level in the past from 0 to 10 4 weeks

Percentage of emotional problems in the past 4 weeks

Daily activities and heat interference category 9-10 Highest 8 High 6-7 Medium 0-5 Low Very much Quite a lot Some Little/none Not at all Slightly Moderate Extreme

\begin{tabular}{|c|c|c|c|c|c|c|c|c|c|c|c|c|}
\hline Sleep (n) & (22132) & (17024) & (12770) & (7052) & (8833) & $(26142)$ & (18968) & (5378) & $(6684)$ & (28752) & (15297) & (8603) \\
\hline Never & 29.5 & 22.9 & 19.7 & 19.7 & 33.2 & 25.3 & 20.2 & 19.6 & 38.6 & 25.4 & 19.3 & 18.6 \\
\hline Sometimes & 30.2 & 34.7 & 35 & 30.1 & 29.9 & 34 & 32.5 & 29.4 & 25.5 & 34.3 & 33.9 & 29.3 \\
\hline Often & 22.2 & 25.7 & 32.2 & 39.8 & 22 & 24.5 & 31.5 & 36.1 & 16.4 & 24 & 32.3 & 38.9 \\
\hline Housework (n) & (22094) & (16992) & $(12748)$ & (7029) & (8827) & (26085) & (18924) & (5364) & (6668) & (28683) & (15273) & (8590) \\
\hline Never & 43.6 & 36.2 & 31 & 30.4 & 46.6 & 39.1 & 31.9 & 30.7 & 53.2 & 38.9 & 31.1 & 29.7 \\
\hline Sometimes & 28 & 34.4 & 35.4 & 30.2 & 26.1 & 32.6 & 33.3 & 31 & 24.2 & 32.8 & 33.6 & 30.4 \\
\hline Often & 27 & 28.2 & 32.5 & 38.4 & 25.9 & 27.1 & 33.6 & 36.8 & 20.8 & 27.1 & 33.9 & 38.9 \\
\hline Daily travel (n) & (22111) & (16994) & (12739) & (7018) & (8829) & (26082) & (18931) & (5355) & (6668) & (28692) & (15275) & (8576) \\
\hline Never & 40.1 & 33.2 & 27.5 & 26.1 & 42.7 & 35.6 & 28.3 & 28 & 49.7 & 35.7 & 27.8 & 25.2 \\
\hline Sometimes & 24.2 & 27.6 & 27.4 & 23.3 & 23.1 & 27.1 & 26 & 23.1 & 21.6 & 27.3 & 16.7 & 22.4 \\
\hline Often & 32.4 & 35.8 & 42.6 & 48.7 & 31.4 & 34.1 & 42.6 & 46.1 & 24.7 & 34 & 42.7 & 50 \\
\hline Work (n) & $(22100)$ & $(17000)$ & $(12744)$ & (7018) & (8831) & $(26101)$ & (18923) & (5362) & (6668) & $(28706)$ & (15279) & (8579) \\
\hline Never & 36.4 & 29.6 & 24.4 & 23.9 & 38.9 & 32 & 25.7 & 24.2 & 45.5 & 32.1 & 24.6 & 22.6 \\
\hline Sometimes & 20.3 & 21.8 & 22.8 & 19.2 & 19.1 & 22.5 & 21 & 19.1 & 17.1 & 22.5 & 22 & 18.9 \\
\hline Often & 29.8 & 33.2 & 38.5 & 44.9 & 30 & 31.4 & 38.7 & 41.5 & 23.7 & 31.1 & 39.7 & 44.7 \\
\hline Exercise (n) & (22080) & (16966) & (12724) & (7016) & (8825) & (26065) & (18895) & (5333) & (6664) & (28668) & (15239) & (8561) \\
\hline Never & 46.8 & 42.6 & 38.8 & 41 & 49.8 & 43.5 & 39.7 & 42.8 & 55.2 & 43.9 & 38.1 & 40.2 \\
\hline Sometimes & 27.8 & 31.8 & 33 & 28.2 & 24.9 & 31.1 & 31.7 & 28.5 & 23.7 & 30.8 & 32.4 & 28.9 \\
\hline Often & 24.6 & 24.8 & 27.4 & 30.2 & 24.7 & 24.6 & 27.7 & 27.9 & 20.1 & 24.5 & 28.8 & 30.2 \\
\hline
\end{tabular}


Table 5 Association between heat interference with daily activities and health and well-being outcomes among cohort members

\begin{tabular}{|c|c|c|c|c|c|c|c|c|c|}
\hline \multirow[b]{3}{*}{$\begin{array}{l}\text { Heat interference } \\
\text { category } \mathrm{N}=60569\end{array}$} & \multicolumn{9}{|c|}{ Adjusted* OR and $95 \% \mathrm{Cl}$} \\
\hline & \multicolumn{3}{|c|}{ Life satisfaction (score 0-10)† } & \multicolumn{3}{|c|}{ Energy level in the past 4 weeks } & \multicolumn{3}{|c|}{ Emotional problems in the past 4 weeks } \\
\hline & $\begin{array}{l}\text { High versus } \\
\text { highest }\end{array}$ & $\begin{array}{l}\text { Medium } \\
\text { versus } \\
\text { highest }\end{array}$ & $\begin{array}{l}\text { Low versus } \\
\text { highest }\end{array}$ & $\begin{array}{l}\text { Quite a lot } \\
\text { versus very } \\
\text { much }\end{array}$ & $\begin{array}{l}\text { Some versus } \\
\text { very much }\end{array}$ & $\begin{array}{l}\text { Little/none } \\
\text { versus very } \\
\text { much }\end{array}$ & $\begin{array}{l}\text { Slightly } \\
\text { versus not at } \\
\text { all }\end{array}$ & $\begin{array}{l}\text { Moderate } \\
\text { versus not at } \\
\text { all }\end{array}$ & $\begin{array}{l}\text { Extreme } \\
\text { versus not at } \\
\text { all }\end{array}$ \\
\hline \multicolumn{10}{|l|}{ Sleep } \\
\hline Never & Ref & Ref & Ref & Ref & Ref & Ref & Ref & Ref & Ref \\
\hline Sometimes & $\begin{array}{l}1.46 \\
(1.37 \text { to } 1.55)\end{array}$ & $\begin{array}{l}1.66 \\
(1.55 \text { to } 1.78)\end{array}$ & $\begin{array}{l}1.42 \\
(1.30 \text { to } 1.55)\end{array}$ & $\begin{array}{l}1.48 \\
(1.38 \text { to } 1.59)\end{array}$ & $\begin{array}{l}1.76 \\
(1.63 \text { to } 1.90)\end{array}$ & $\begin{array}{l}1.65 \\
(1.48 \text { to } 1.84)\end{array}$ & $\begin{array}{l}1.94 \\
(1.80 \text { to } 2.10)\end{array}$ & $\begin{array}{l}2.48 \\
(2.28 \text { to } 2.70)\end{array}$ & $\begin{array}{l}2.23 \\
\text { (2.02 to } 2.46)\end{array}$ \\
\hline Often & $\begin{array}{l}1.50 \\
(1.41 \text { to } 1.60)\end{array}$ & $\begin{array}{l}2.10 \\
(1.95 \text { to } 2.25)\end{array}$ & $\begin{array}{l}2.49 \\
(2.28 \text { to } 2.71)\end{array}$ & $\begin{array}{l}1.52 \\
(1.40 \text { to } 1.64)\end{array}$ & $\begin{array}{l}2.44 \\
(2.25 \text { to } 2.64)\end{array}$ & $\begin{array}{l}2.91 \\
(2.61 \text { to } 3.25)\end{array}$ & $\begin{array}{l}2.27 \\
(2.07 \text { to } 2.48)\end{array}$ & $\begin{array}{l}3.86 \\
(3.50 \text { to } 4.26)\end{array}$ & $\begin{array}{l}4.81 \\
(4.32 \text { to } 5.36)\end{array}$ \\
\hline \multicolumn{10}{|l|}{ Housework } \\
\hline Never & ef & Ref & Ref & Ref & - & Ref & Ref & Ref & Ref \\
\hline Sometimes & $\begin{array}{l}1.42 \\
(1.35 \text { to } 1.50)\end{array}$ & $\begin{array}{l}1.65 \\
(1.56 \text { to } 1.76)\end{array}$ & $\begin{array}{l}1.44 \\
(1.33 \text { to } 1.56)\end{array}$ & $\begin{array}{l}1.46 \\
(1.36 \text { to } 1.56)\end{array}$ & $\begin{array}{l}1.76 \\
\text { (1.64 to } 1.89)\end{array}$ & $\begin{array}{l}1.70 \\
(1.54 \text { to } 1.87)\end{array}$ & $\begin{array}{l}1.79 \\
\text { (1.66 to } 1.93)\end{array}$ & $\begin{array}{l}2.21 \\
(2.04 \text { to } 2.39)\end{array}$ & $\begin{array}{l}2.05 \\
(1.87 \text { to } 2.24)\end{array}$ \\
\hline Often & $\begin{array}{l}1.32 \\
(1.25 \text { to } 1.40)\end{array}$ & $\begin{array}{l}1.79 \\
(1.68 \text { to } 1.90)\end{array}$ & $\begin{array}{l}2.11 \\
(1.95 \text { to } 2.28)\end{array}$ & $\begin{array}{l}1.31 \\
(1.22 \text { to } 1.40)\end{array}$ & $\begin{array}{l}2.04 \\
(1.89 \text { to } 2.19)\end{array}$ & $\begin{array}{l}2.34 \\
(2.13 \text { to } 2.58)\end{array}$ & $\begin{array}{l}1.82 \\
(1.68 \text { to } 1.96)\end{array}$ & $\begin{array}{l}2.86 \\
(2.62 \text { to } 3.11)\end{array}$ & $\begin{array}{l}3.35 \\
(3.05 \text { to } 3.67)\end{array}$ \\
\hline \multicolumn{10}{|l|}{ Daily travel } \\
\hline Never & ef & Ref & Ref & Ref & & Ref & Ref & Ref & Ref \\
\hline Sometimes & $\begin{array}{l}1.36 \\
(1.28 \text { to } 1.44)\end{array}$ & $\begin{array}{l}1.60 \\
(1.49 \text { to } 1.70)\end{array}$ & $\begin{array}{l}1.36 \\
(1.25 \text { to } 1.49)\end{array}$ & $\begin{array}{l}1.40 \\
(1.30 \text { to } 1.50)\end{array}$ & $\begin{array}{l}1.66 \\
(1.54 \text { to } 1.79)\end{array}$ & $\begin{array}{l}1.51 \\
\text { (1.35 to } 1.67)\end{array}$ & $\begin{array}{l}1.64 \\
(1.52 \text { to } 1.77)\end{array}$ & $\begin{array}{l}2.00 \\
(1.84 \text { to } 2.18)\end{array}$ & $\begin{array}{l}1.78 \\
\text { (1.61 to } 1.97)\end{array}$ \\
\hline Often & $\begin{array}{l}1.33 \\
(126 \text { to } 1.41)\end{array}$ & $\begin{array}{l}1.82 \\
(1.72 \text { to } 1.94)\end{array}$ & $\begin{array}{l}2.13 \\
(1.97 \text { to } 2.30)\end{array}$ & $\begin{array}{l}1.36 \\
(1.28 \text { to } 1.46)\end{array}$ & $\begin{array}{l}2.13 \\
(1.98 \text { to } 2.28)\end{array}$ & $\begin{array}{l}2.30 \\
(2.10 \text { to } 2.53)\end{array}$ & $\begin{array}{l}1.85 \\
(1.71 \text { to } 1.99)\end{array}$ & $\begin{array}{l}2.82 \\
(2.60 \text { to } 3.06)\end{array}$ & $\begin{array}{l}3.51 \\
(3.21 \text { to } 3.85)\end{array}$ \\
\hline \multicolumn{10}{|c|}{ (1) } \\
\hline Never & Ref & Ref & Ref & Ref & Ref & Ref & Ref & Ref & Ref \\
\hline Sometimes & $\begin{array}{l}1.32 \\
(1.24 \text { to } 1.40)\end{array}$ & $\begin{array}{l}1.63 \\
(1.52 \text { to } 1.75)\end{array}$ & $\begin{array}{l}1.40 \\
(1.28 \text { to } 1.54)\end{array}$ & $\begin{array}{l}1.40 \\
(1.30 \text { to } 1.51)\end{array}$ & $\begin{array}{l}1.65 \\
(1.52 \text { to } 1.80)\end{array}$ & $\begin{array}{l}1.64 \\
(1.46 \text { to } 1.84)\end{array}$ & $\begin{array}{l}1.78 \\
\text { (1.63 to } 1.93)\end{array}$ & $\begin{array}{l}2.22 \\
(2.03 \text { to } 2.44)\end{array}$ & $\begin{array}{l}2.08 \\
\text { (1.87 to } 2.32)\end{array}$ \\
\hline Often & $\begin{array}{l}1.37 \\
(1.30 \text { to } 1.45)\end{array}$ & $\begin{array}{l}1.87 \\
(1.75 \text { to } 1.99)\end{array}$ & $\begin{array}{l}2.17 \\
\text { (2.01 to } 2.36)\end{array}$ & $\begin{array}{l}1.36 \\
(1.27 \text { to } 1.45)\end{array}$ & $\begin{array}{l}2.13 \\
(1.98 \text { to } 2.29)\end{array}$ & $\begin{array}{l}2.45 \\
(2.22 \text { to } 2.71)\end{array}$ & $\begin{array}{l}1.85 \\
(1.71 \text { to } 1.99)\end{array}$ & $\begin{array}{l}2.96 \\
(2.73 \text { to } 3.24)\end{array}$ & $\begin{array}{l}3.64 \\
\text { (3.31 to } 4.00)\end{array}$ \\
\hline \multicolumn{10}{|c|}{ (1) } \\
\hline Never & Ref & Ref & Ref & Ref & Ref & Ref & Ref & Ref & Ref \\
\hline Sometimes & $\begin{array}{l}1.26 \\
(1.19 \text { to } 1.33)\end{array}$ & $\begin{array}{l}1.40 \\
(1.32 \text { to } 1.48)\end{array}$ & $\begin{array}{l}1.10 \\
(1.02 \text { to } 1.18)\end{array}$ & $\begin{array}{l}1.41 \\
(1.32 \text { to } 1.51)\end{array}$ & $\begin{array}{l}1.58 \\
(1.48 \text { to } 1.70)\end{array}$ & $\begin{array}{l}1.33 \\
(1.21 \text { to } 1.46)\end{array}$ & $\begin{array}{l}1.57 \\
(1.45 \text { to } 1.71)\end{array}$ & $\begin{array}{l}1.90 \\
(1.75 \text { to } 2.05)\end{array}$ & $\begin{array}{l}1.55 \\
\text { (1.42 to } 1.69)\end{array}$ \\
\hline Often & $\begin{array}{l}1.17 \\
(1.11 \text { to } 1.24)\end{array}$ & $\begin{array}{l}1.42 \\
(1.33 \text { to } 1.51)\end{array}$ & $\begin{array}{l}1.38 \\
(1.28 \text { to } 1.49)\end{array}$ & $\begin{array}{l}1.24 \\
(1.16 \text { to } 1.33)\end{array}$ & $\begin{array}{l}1.59 \\
(1.48 \text { to } 1.71)\end{array}$ & $\begin{array}{l}1.57 \\
(1.43 \text { to } 1.73)\end{array}$ & $\begin{array}{l}1.58 \\
(1.46 \text { to } 1.71)\end{array}$ & $\begin{array}{l}2.16 \\
(1.98 \text { to } 2.35)\end{array}$ & $\begin{array}{l}2.14 \\
(1.94 \text { to } 2.35)\end{array}$ \\
\hline
\end{tabular}

*Multivariate regression adjusting for potential confounders: age, sex, marital status, work status, household income, urban-rural residence, exercise, housework, hours of sleep, body mass index, smoking and drinking.

†Life satisfaction scores: highest=9-10, high $=8$, medium $=6-7$ and low $=0-5$. 
lower motivation to work and experienced more negative moods in hot environments. Anderson found that the prolonged, continuous repetitive actions required to maintain performance at work and achieve target goals (such as getting a job finished) can lead to hypertension. ${ }^{32}$ And when more effort was required to complete a task in hot conditions loss of motivation was experienced leading to lower productivity and increased injury risk. The impact of heat stress on psychological performance variables ${ }^{11}$ is a likely factor in these work-related impacts of heat.

Psychological effects of heat stress have been noted in other settings as well. Nitschke $e t a l^{33}$ reported a positive association between high-ambient temperature and hospital admissions for mental and behavioural disorders in Adelaide, Australia. Specific illnesses for which admissions increased included anxiety, symptomatic mood disorders and psychological development disorders among elderly people when temperature exceeded $26.7^{\circ} \mathrm{C} .{ }^{34}$ Moreover, excessive heat stress exposure may also increase violence. ${ }^{32-35}$ Increasing heat stress had been associated with higher rates of aggressive behaviour, ${ }^{36}$ and higher violent suicide rates. ${ }^{37}$ In a meta-analysis, Bouchama $e t a l^{8}$ concluded that pre-existing mental health problems tripled the risk of all-cause mortality during a heat wave. A related issue is the physical and psychological exhaustion caused by extreme heat stress. ${ }^{7}$

In our study, we found that heat stress in Thailand is not only a problem at work but also heat stress interferes with other daily activities including sleeping, daily travel, housework and exercise. The results of our study complement other Thai research about adverse effects of heat. One recent report shows that heat stress in Thailand is a very serious problem in a wide variety of work settings. ${ }^{18}$ McMichael et $a l^{19}$ and Guo et $a l^{99}$ found a temperature-mortality association and Pudpong and Hajat $^{20}$ found heat-related excess hospital admissions. Worker studies in Thailand related occupational heat stress, kidney disease and psychological distress. ${ }^{10} 21$

One limitation of this study is that it could not directly establish that health and well-being outcomes arose as a result of heat stress. Interpreting causality between heat stress exposure and health and well-being outcomes is complex in a cross-sectional study as we cannot be completely sure that heat stress preceded their health condition and well-being. Also, the source of the heat stress was not reported and we could not make direct measurements of heat stress exposure and health and well-being outcomes. Another limitation of this study arose because people answered the questionnaire at different times of the year (but most in March-July-the hot period). The questions on physical and emotional health assessed the previous 4 weeks so most (almost all) were answering for the hot period.

The strength of this study is its large scale with participation from a national group of adults embedded in the socioeconomic mainstream of Thai society. Other strengths include the comprehensive questionnaire which captures a detailed assessment of health and an array of geodemographic, environmental and social attributes. Also, the cohort has been set up for future longitudinal analysis which will provide better insight into causal pathways between heat stress and subsequent health outcomes in the long run.

We conclude that Thai populations are at high risk of heat stress during daily activities. Also, in Thailand an anticipated increase in temperature from climate change plus the ageing and urbanisation of the population could significantly increase heat impacts on health and well-being. There is a need for improvements in public health surveillance and public awareness regarding the risks of heat stress which hitherto have been considered unremarkable in such a tropical environment.

\section{Author affiliations}

${ }^{1}$ National Centre for Epidemiology and Population Health, ANU College of Medicine, Biology and Environment, the Australian National University, Canberra, Australia

${ }^{2}$ Health Impact Assessment Division, Department of Health, Ministry of Public Health, Nonthaburi, Thailand

${ }^{3}$ Centre for Global Health Research, Umeå University, Umeå, Sweden ${ }^{4}$ School of Human Ecology, Sukhothai Thammathirat Open University, Nonthaburi, Thailand

Acknowledgements We thank the staff at Sukhothai Thammathirat Open University (STOU) who assisted with student contact, and the STOU students who are participating in the cohort study. We also thank Dr Bandit Thinkamrop and his team from Khon Kaen University for guiding us successfully through the complex data processing.

Collaborators Thailand: Jaruwan Chokhanapitak, Chaiyun Churewong, Suttanit Hounthasarn, Suwanee Khamman, Daoruang Pandee, Suttinan Pangsap, Tippawan Prapamontol, Janya Puengson, Yodyiam Sangrattanakul, Sam-ang Seubsman, Boonchai Somboonsook, Nintita Sripaiboonkij, Pathumvadee Somsamai, Duangkae Vilainerun and Wanee Wimonwattanaphan. Australia: Chris Bain, Emily Banks, Cathy Banwell, Bruce Caldwell, Gordon Carmichael, Tarie Dellora, Jane Dixon, Sharon Friel, David Harley, Matthew Kelly, Tord Kjellstrom, Lynette Lim, Roderick McClure, Anthony McMichael, Tanya Mark, Adrian Sleigh, Lyndall Strazdins and Vasoontara Yiengprugsawan.

Contributors The corresponding author had full access to all data used in the study and had final responsibility for the decision to submit for publication. BT and $V Y$ conceptualised the analysis for this paper with contributions from all authors. BT and VY wrote the first draft. BT did the literature search and VY did statistical analyses. TK had the initial idea for the heat stress study. SS and AS conceived and executed the Thai Cohort Study and assisted with the writing and interpretation. All authors contributed to and approved the final version.

Funding The International Collaborative Research Grants Scheme with joint grants from the Wellcome Trust UK (GR071587MA) and the Australian National Health and Medical Research Council (NHMRC 268055), and as a global health grant from the NHMRC (585426).

\section{Competing interests None.}

Ethics approval Sukhothai Thammathirat Open University Research and Development Institute (protocol 0522/10) and the Australian National University Human Research Ethics Committee (protocol 2009/570).

Provenance and peer review Not commissioned; externally peer reviewed.

Data sharing statement Statistical code in Stata, and dataset available from the corresponding author at ben_5708@hotmail.com. All Participants gave informed consent and the presented data in this manuscript are anonymous. 


\section{REFERENCES}

1. Confalonieri U, Menne B, Akhtar R, et al. Human health. Climate change 2007: impacts, adaptation and vulnerability, contribution of working group II to the fourth assessment report of the intergovernmental panel on climate change. Cambridge, UK: Cambridge University Press, 2007 (cited 13 March 2012); http://www.ipcc-wg2.org (accessed 13 March 2012).

2. Basu R, Samet JM. Relation between elevated ambient temperature and mortality: a review of the epidemiologic evidence. Epidemiol Rev 2002;24:190-202.

3. Kovats RS, Hajat S. Heat stress and public health: a critical review. Annu Rev Public Health 2008;29:41-55.

4. Basu R. High ambient temperature and mortality: a review of epidemiologic studies from 2001 to 2008. Environ Health 2009;8:40.

5. Bi P, Williams S, Loughnan M, et al. The effects of extreme heat on human mortality and morbidity in Australia: implications for public health. Asia Pac J Public Health 2011;23(2 Suppl):27S--36S.

6. Campbell-Lendrum D, Corvalan C. Climate change and developing-country cities: implications for environmental health and equity. J Urban Health 2007;84(1 Suppl):i109-17.

7. Parsons K. Human thermal environments: the effects of hot, moderate, and cold environments on human health, comfort and performance. 2nd edn. London: Taylor \& Francis, 2003.

8. Kjellstrom T. Climate change, direct heat exposure, health and well-being in low and middle-income countries. Glob Health Action 2009;2:1-3.

9. Berry HL, Bowen K, Kjellstrom T. Climate change and mental health: a causal pathways framework. Int J Public Health 2010;55:123-32.

10. Tawatsupa B, Lim LL-Y, Kjellstrom T, et al. The association between overall health, psychological distress, and occupational heat stress among a large national cohort of 40913 Thai workers. Glob Health Action 2010;3:1-10.

11. Hancock PA, Ross JM, Szalma JL. A meta-analysis of performance response under thermal stressors. Hum Factors 2007;49:851-77.

12. Kjellstrom T. Climate change exposures, chronic disease and mental health in urban populations:a threat to health security, particularly for the poor and disadvantaged. Kobe, Japan: World Health Organization Centre for Health and Development, 2009.

13. Kjellstrom T, Holmer I, Lemke B. Workplace heat stress, health and productivity-an increasing challenge for low and middle-income countries during climate change. Glob Health Action 2009;2:1-6.

14. Kjellstrom T, Gabrysch S, Lemke B, et al. The 'Hothaps' program for assessing climate change impacts on occupational health and productivity: an invitation to carry out field studies. Glob Health Action 2009;2:1-7.

15. Tawatsupa B, Dear K, Kjellstrom T, et al. The association between temperature and mortality in tropical middle income Thailand from 1999 to 2008. Int J Biometeorol 2012:1-13.

16. Limsakul A, Goes Jl. Empirical evidence for interannual and longer period variability in Thailand surface air temperatures. Atmos Res 2008;87:89-102

17. Thai Meteorological Department. Climate change in Thailand for last 52 years. Bangkok: Meteorological Department, Thailand, 2007. http://www.tmd.go.th/info/info.php?FilelD=86 (accessed 4 Feb 2012)

18. Langkulsen U, Vichit-Vadakan N, Taptagaporn S. Health impact of climate change on occupational health and productivity in Thailand. Glob Health Action 2010;3:1-9.
19. McMichael AJ, Wilkinson P, Kovats RS, et al. International study of temperature, heat and urban mortality: the 'ISOTHURM' project. Int $J$ Epidemiol 2008;37:1121-31.

20. Pudpong N, Hajat S. High temperature effects on out-patient visits and hospital admissions in Chiang Mai, Thailand. Sci Total Environ 2011;409:5260-7.

21. Tawatsupa B, Lim LL-Y, Kjellstrom T, et al. Association between occupational heat stress and kidney disease among 37816 workers in the Thai Cohort Study (TCS). J Epidemiol 2012;22:251-60.

22. Sleigh A, Seubsman S, Bain C. Cohort profile: the Thai Cohort of 87134 Open University students. Int J Epidemiol 2008;37:266-72.

23. Grad FP. The preamble of the constitution of the World Health Organization. Bull World Health Organ 2002;80:981-4.

24. Cummins RA, Eckersley R, Pallant J, et al. Developing a national index of subjective wellbeing: the Australian Unity Wellbeing Index. Soc Indic Res 2003;64:159-90.

25. Yiengprugsawan V, Seubsman S, Khamman S, et al. Personal wellbeing index in a national cohort of 87134 Thai adults. Soc Indic Res 2010;98:201-15.

26. StataCorp. Stata 12.0 for windows. College Station, TX: StataCorporation, 2011.

27. Kanazawa M, Yoshiike N, Osaka T, et al. Criteria and classification of obesity in Japan and Asia-Oceania. Asia Pac J Clin Nutr 2002;11: S732-7.

28. Hajat S, O'Connor M, Kosatsky T. Health effects of hot weather: from awareness of risk factors to effective health protection. Lancet 2010;375:856-63

29. McMichael AJ, Woodruff RE, Hales S. Climate change and human health: present and future risks. Lancet 2006;367:859-69.

30. Kjellstrom T, Butler AJ, Lucas RM, et al. Public health impact of global heating due to climate change: potential effects on chronic non-communicable diseases. Int J Public Health 2010;55:97-103.

31. Lan L, Lian Z, Pan L. The effects of air temperature on office workers' well-being, workload and productivity-evaluated with subjective ratings. Appl Ergon 2010;42:29-36

32. Anderson C. Heat and violence. Curr Dir Psychol Sci 2001;10:33-8.

33. Nitschke M, Tucker GR, Bi P. Morbidity and mortality during heatwaves in metropolitan Adelaide. Med J Aust 2007;187:662-5.

34. Hansen AL, Bi P, Nitschke M, et al. The effect of heat waves on mental health in a temperate Australian city. Environ Health Perspect 2008;116:1369-75.

35. Anderson $\mathrm{C}$, Anderson K, Dorr N, et al. Temperature and aggression. Adv Exp Soc Psychol 2000;32:63-133.

36. Cheatwood D. The effects of weather on homicide. J Quant Criminol 1995;11:51-70.

37. Maes M, De Meyer F, Thompson $\mathrm{P}$, et al. Synchronized annual rhythms in violent suicide rate, ambient temperature and the light-dark span. Acta Psychiatr Scand 1994;90:391-6.

38. Bouchama A, Dehbi M, Mohamed G, et al. Prognostic factors in heat wave-related deaths: a meta-analysis. Arch Intern Med 2007;167:2170-6.

39. Guo Y, Punnasiri K, Tong S. Effects of temperature on mortality in Chiang Mai city, Thailand: a time series study. Environ Health 2012;11:36. 